\title{
0 universo de crenças na argumentação da publicidade
}

\begin{abstract}
RESUMO
O modo de organização argumentativo constitui o mecanismo que permite a construção de um universo de crenças, a partir de asserções feitas a propósito do mundo numa perspectiva demonstrativa ou persuasiva. A demonstrativa estabelece as ligações de causalidade e a persuasiva elabora a prova com o auxilio dos argumentos, que justificam os propósitos sobre o mundo e as ligações de causalidade, a partir da relação entre as asserções. Como o corpus é formado por anúncios publicitários, a forma de organização argumentativa será estudada com maior destaque, através da teoria semiolinguística de Patrick Charaudeau, que permite a análise da situação comunicativa com as noções de propósito, da proposição e da persuasão, que impõem estratégias de diferenciação, utilizando a singularidade nos discursos da concorrência.
\end{abstract}

\section{PALAVRAS-CHAVE \\ publicidade \\ discurso \\ argumentação}

\begin{abstract}
The modo of an argumentative organization constitutes the mechanism that allows the construction of an universe of faiths, starting from assertions made concerning the world in a demonstrative or persuasive. Perspective demonstrative one establishes the causality connections and the persuasive one elaborates the proof with I aid him of the arguments, that justify the purposes about the world and the causality connections, starting from the relationship among the assertions. As the corpus is formed by advertising announcements, the argumentative organization form will be studied with larger prominence, through Patrick Charaudeau's semiolinguistic theory, that allows the analysis of the communicative situation on purpose with the notions, of the proposition and of the persuasion, that they impose differentiation strategies, using the singularity in the speeches of the competition.
\end{abstract}

\section{KEY WORDS}

publicity

speak

argument

\section{Maria Helena Steffens de Castro PUCRS \\ mariahs@terra.com.br}

Existe uma longa tradição filosófica e lingüística que permite resgatar uma história da argumentação. Desde a Antigüidade clássica os gregos fizeram da argumentação a arte de seduzir e persuadir, pela consciência que tinham de que "ter influência sobre o outro" não era atributo da razão (ratio), uma vez que o indivíduo é igualmente influenciado por paixões. Desde então, estava estabelecida a distinção entre o que pertence ao raciocínio, ou seja à razão, e o que pertence à persuasão, correspondente à técnica expressiva de "emocionar e captar um auditório", pela capacidade em conquistar o outro pelo sentimento afetivo.

Chaim Perelman et al.(1996), recuperam na teoria da argumentação a retórica (menosprezada pela tradição platônica), que não tem como fim único a adesão intelectual do auditório, mas visa incitar à ação ou, criar uma disposição ao consumo. O discurso dirigido ao auditório particular destina-se à persuasão, enquanto o que se dirige ao auditório universal visa a um convencimento sobre os fatos.

Desse modo, argumentar é uma atividade que inclui numerosos procedimentos, mas o que distingue esses procedimentos de outros modos discursivos é o fato de usarem a racionalidade nas percepções do mundo e das ações humanas, trabalhando o raciocínio que é marcado por uma lógica e uma princípio de não contradição.(Charaudeau,1992)

Toda afirmação pode ser argumentativa a partir do momento em que se insere em um dispositivo argumentativo e pode ser anulada em seu próprio fundamento ou em sua validade pela contestação, caso não logre superá-la. Para definir esse dispositivo, o sujeito é levado a tomar uma posição, utilizando certas estratégias de natureza semântica discursiva e de composição, confirmando o papel de sujeito persuasivo que tenta provar uma verdade sobre o mundo. Reencontram-se aqui certas leis do discurso como a homogeneidade, a lógica, a progressão, a clareza, o falar a propósito, cuja intenção é manter empatia com o ouvinte e conseguir credibilidade, possibilitando variedades interlocutivas, no momento em que forem contestadas ou contra-argumentadas.

Em seu estudo sobre o discurso da mídia, Charaudeau (2006) afirma que na publicidade parte-se da hipótese, que a finalidade do contrato sociolinguageiro, ou o projeto de fala dos redatores das mensagens, é transformar, por meio da persuasão, um leitor de publicidade em um consumidor efetivo de mercadorias. Para alcançar seus objetivos, adotam estratégias de captação que ocultam, na maior parte das vezes, a finalidade comercial do projeto publicitário, tentando associá-lo à situações que fazem parte do imaginário coletivo do sujeito 
interpretante, transformando seu desejo em legitimações coletivas sobre tendências associadas aos valores adotados por uma sociedade.

A simples presença de asserções não implica em uma argumentação, pois é necessário que as asserções se inscrevam num "dispositivo argumentativo" que se compõe de três quadros: o propósito (tese), a proposição e a persuasão. Asserções e encadeamento de asserções vão se combinando no discurso para formar o propósito, que afirma coisas sobre os fenômenos do mundo. Entretanto, para que o processo argumentativo se desenvolva, é preciso que o sujeito que argumenta assuma posição em relação a veracidade desse propósito, falando em seu nome ou em nome de outro, manifestando-se sobre o que sustenta sua argumentação.

O sujeito para argumentar, vale-se de procedimentos lingüísticos com a função essencial de tornar válida sua argumentação, na tentativa de mostrar que o quadro de questionamento é justificado e confiável, demonstrando domínio de saber em relação ao que afirma .

Não basta entretanto, que o sujeito emita proposições sobre o que está sendo discutido, é preciso que essas se inscrevam num quadro de questionamento que poderá produzir um ato persuasivo, na tentativa de contestar ou provar a veracidade do que foi proposto. Nesse caso, o contrato de fala caracteriza-se como situacional, pois emite uma consciência social mutável ao configurar a argumentação através de marcas lingüísticas de uma determinada sociedade.

Quando o texto deixa claro qual é a proposta, em que consiste a proposição e qual vai ser o quadro de persuasão, apresenta-se um contrato explícito. Nos implícitos, entretanto, "o dispositivo não é precisado, tornando-se necessário, interpretar os significados ocultos nos argumentos simples como participantes do dispositivo argumentativo." (Charaudeau, 1992:810).

Assim: "Ninguém é bela por acaso. Natura". Deve ser interpretado com a lógica de um texto publicitário, que implicitamente afirma, que somente o uso de produtos da Natura faz com a beleza seja possível.

Mesmo a proposição não é suficiente ainda para que se desenvolva a argumentação. É necessário que o sujeito prove a veracidade de sua proposta ao desenvolver o ato de persuasão, ou seja, adotando um quadro de raciocínio persuasivo ao longo de sua fala, recorrendo a procedimentos semânticos, discursivos e de composição a fim de elaborar sua prova.

A persuasão então, como parte do processo argumentativo, repousa sobre um princípio de não-contradição, de rigor lógico, de verossimilhança em relação à proposta feita, como ideal do saber dizer, buscando a adesão de um parceiro ao universo do outro. $O$ autor considera que, na argumentação, a razão demonstrativa deve se unir a uma razão persuasiva, dependendo do sujeito que argumenta e da situação em que ambos se encontram ligados, por certo contrato de comunicação, que fornece as chaves de interpretação do texto.

\section{A materialização do consumo}

O contrato de comunicação adotado pela publicidade sempre jogou com o prosaico e com o poético, apresentando com arte um objeto, de modo que se tornasse único e original, por meio de palavras e de imagens que buscassem a harmonia, o ritmo, a clareza e a precisão. Jakobson (1971) já dizia que o estudo da poética não deve se restringir à literatura, mas abranger outros discursos em que os traços poéticos possam ser encontrados, como acontece na publicidade, pois o homem antes de ser um consumidor de produtos é um consumidor de palavras. Por isso, o discurso publicitário, não obstante seja considerado pelos literatos um discurso não literário, usa as palavras e as frases para argumentar, como quem faz um poema, pois a poesia tem em comum com a propaganda o fato de ser uma glorificação da síntese e um voltar-se sobre si, como afirma Valéry (1987).

Nos primeiros anos de atividade, a publicidade, no entanto, mostrou-se predominantemente informativa, para orientar sobre seus códigos e processos, sedimentando, no leitor, um tipo de conhecimento que lhe foi dando condições de distinguir um anúncio de outro tipo de texto veiculado numa revista ou jornal. Foi possível criar mensagens que empregassem preferencialmente as modalidades coloquiais, assumindo compromisso com a novidade e com a atualidade com um consumidor idealizado pelos produtores, adequando-se a sua função persuasiva e utilitária. A criatividade não visava à transcendência, como na arte, mas buscava soluções que revelassem a realidade, tornando-a mais desejada e valorizada pelo conhecimento prático do que pela surpresa da descoberta.

O publicitário percebia que a leitura de um anúncio servia para reproduzir relações sociais da vida cotidiana, encontradas na literatura, nas relações amorosas, na religião entre outras. Ao pretender comunicar-se com seu público precisava falar a linguagem da comunidade, baseada no sentido comum e formada pela necessidade prática da vida. As expressões lingüísticas usadas então, retratavam significados variáveis do potencial social e cultural do país.

No assentamento dos domínios da comunicação, a linguagem publicitária recorria a estratégias que iam da generalização à singularização do produto, procurando torná-lo único aos olhos do consumidor. Não é estranho, pois, que à margem das particularidades de seu uso social, a linguagem publicitária adquiria um domínio universal, refletindo no realismo das palavras o reflexo de um tempo, da expressão de uma época e do viver de uma comunidade.

Nos anúncios da década de 40, da Revista do Globo que foi publicada em Porto Alegre, fica evidente que os processos argumentativos dependiam estritamente das formas retóricas e enunciativas empregadas na época, como o resultado de uma combinação particular entre a linguagem publicitária e o tipo de discurso de uma sociedade tradicional, que precisava ser convencida das 
qualificações particulares dos produtos que chegavam ao mercado.

Como estratégia adotava um discurso argumentativo que empregava a singularização, como processo destinado a convencer o destinatário de que o produto anunciado se distinguia dos demais, por seus benefícios exclusivos, como aparece nos exemplos:

Rouge Colgate dura cinco vezes mais.

Além de evitar o mau hálito Colgate limpa e dá brilho aos dentes.

Também nos textos sobre o sabonete Lever fica implícito que o uso do produto evidenciava o aspecto sedutor da mulher, argumento que se apoiava em depoimentos de atrizes de cinema de Hollywood, confirmando a exclusividade do produto:

A espuma especial do sabonete Lever torna minha pele mais clara, aveludada e juvenil (Rita Hayworth)

Também nos anúncios da Revista do Globo, escritos em forma de verso, aparece a singularização de um desejo, expressa de maneira implícita e sutilmente lógica, como se destaca nos exemplos:

É com brazinhas e não com brazões que ‘Geral' é o rei dos fogões! (Fogão Geral)

E este não será completo

(e não será com razão)

se não for confeccionado

com Rendas Feitas a Mão. (Casa A Nortista)

Kolynos dá sorriso mais brilhante

Kolynos rende mais ... é refrescante. (Creme dental Kolynos)

Charaudeau analisa a singularização como o processo destinado a antecipar o contrato da argumentação, na tentativa de convencer, de diferentes maneiras, que a implicação é absoluta e verdadeira, distinguindo o produto dos demais, tornando-se o único a proporcionar os benefícios procurados pela mulher, destinatária do enunciado.

O propósito sobre o qual se constrói a argumentação, apresentava os produtos garantidos pelas qualidades de bom gosto e preço acessível; do esforço e do valor; do fortalecimento dos órgãos do corpo; da harmonia e do bem estar; da beleza e da sedução, além do vigor e da coragem.

Os anúncios dos produtos que chegavam ao mercado são apresentados com qualidades próprias da década de 40 e prometiam proporcionar um enxoval distinto à noiva; uma bela cabeleira ao usuário do Tricófero de Barry; uma afinada voz e dentes brilhantes aos eventuais consumidores de Bromil e Kolynos; poder de sedução para quem usasse Van Ess e Sobrancil; o corpo forte para o consumidor da Aveia Quaker e um casamento harmonio- so com Neocid, pois ele eliminava "os insetos que podem cair na sopa do marido na hora do jantar e acabar com o casamento".

Nos anúncios de contrato explícito, o texto define de forma direta o propósito, como se observa nos exemplos: Se este é o teu Caso à Casa Seabra vai.

Ali tens da elegância o primaciado \,

Mantido com prestígio que não cai,

Como a primeira Casa de Calçado. (Casa Seabra)

Meu amor escuta aqui

Vou revelar-te um segredo

Só a pele bonita tem

Quem usa o creme Irai! (Creme Irai1)

Minha pele era tão feia,

Que eu mesma tinha tristeza:

Agora uso Antisardina,

E ela está que é uma beleza! (Antisardina)

A proposição aparece desenvolvida ao longo dos textos dos anúncios, que apresentavam alternativas orientadas para a possibilidade de realçar a beleza e fazê-la atingir o grau máximo de sedução, incitando o sujeito interpretante a se identificar com uma imagem ideal de destinatário, funcionando como agente de uma ação, em que a mulher que usar Antisardina será a beneficiária.. Também aparecem argumentos que destacam a saúde do corpo em geral e mudança de hábitos e costumes. Ficam evidenciados, também, aspectos ligados à tradição, numa época em que as mulheres faziam enxoval com bordados e rendas feitas à mão, cozinhavam para a família e se responsabilizavam pela saúde e pelo bem estar do marido e filhos. Em alguns anúncios aparecem justificativas para mudanças nessas estruturas tradicionais, como por exemplo:

$\mathrm{Na}$ época atual não é necessário nascer bela ... Personalidade, bom gosto e um mak-up elegantemente aplicado, sempre vale mais do que o perfil clássico.

(Creme Antisardina)

A persuasão tenta responder antecipadamente às objeções do destinatário em relação à rejeição dos benefícios que os produtos anunciam, ou à possível existência de outros oferecidos pela concorrência, como nos exemplos:

Antisardina é barata / e dos cremes é o primeiro;

Só a pele bonita tem / Quem usa o creme Irai ;

Caracterizado pela impessoalidade, esses enunciados conservam todos os sinais exteriores de distanciamento, no momento em que o enunciador deixa de falar explicitamente ao leitor de anúncio para se tornar o narrador de uma história ou a figura anônima do sujeito que apresenta os fatos, simuladores da ordem normal do mundo. As mensagens mostram universos significantes abertos aos percursos dos sujeitos interpretantes e pos- 
síveis consumidores do produto através de fenômenos de identificação com a cena representada.

A análise evidencia, nos anúncios da RG escritos em forma de versos, a predominância do discurso de sedução sobre o de persuasão, através de um "contrato do maravilhoso", pois pretende atingir um público menos racionalista e mais inclinado a sonhar, a imaginar mundos ligados às fantasias criadas nos textos. O produto ocupa, então, uma função quase mágica, como estratégia para convencer o sujeito interpretante de que ele tem uma carência, o que provoca de sua parte uma ação para tentar satisfazer esse desejo através da aquisição e o uso do produto.

Esse processo, segundo Charaudeau (1983), leva o sujeito real a assumir a identidade do ator da história, fazendo com que o produto extrapole suas necessidades concretas e satisfaça seus desejos imaginários, ligados à sedução da beleza, da elegância e da felicidade.

Aldous Huxley ${ }^{1}$, já em 1941, definia a publicidade como uma linguagem da literatura e relacionava seu discurso com uma forma literária aplicada e rebelde, uma vez que o poeta escreve sonetos para si mesmo, mas a publicidade sempre pensou num público amplo e variado. Logo, o estilo da mensagem e as idéias veiculadas devem ser suficientemente claras, simples e de fino trato, sem usar jamais a vulgaridade.

Já para Ferrer (1994, p. 45), a publicidade adota uma linguagem que "tiene no solo analojias, sino herancias del linguaje poético, sea en el uso de metáfora como enriquecimiento de la palabra seductora, sea porque los publicistas, al estilo de los poetas, buscan com los distinctos efectos semejantes bajo almarco del asombro y de la surpresa".

Como o texto publicitário não só participa de uma constante superposição de códigos, como também, estabelece relação com outros sistemas textuais, converte-se num híbrido ao convocar outras variedades discursivas para extrair delas todos os recursos argumentativos que permitam consolidar sua própria postura. Isso porque, na argumentação, a razão demonstrativa se une a uma razão persuasiva, que para Charaudeau (1983) depende do sujeito que argumenta e da situação em que se encontra em relação ao destinatário, já que participam de um contrato de fala, que se realiza, numa metalinguagem metafórica, entre um benfeitor (EUe) e um beneficiário (TUd), acerca de diferentes benefícios que um produto ou serviço possa lhes proporcionar, além de suas qualificações práticas.

O sujeito comunicante, ou o produtor da mensagem, dispõe de estratégias que se manifestam através da organização enunciativa e da discursiva no ato de linguagem, ocultando a finalidade comercial da publicidade. Essa ocultação, para Charaudeau, se realiza quando o sujeito enunciativo se apresenta como sujeito comunicante/ publicitário.

Já o consumidor é marcado pela imagem de sujeito destinatário que está interessado, não pelo produto, mas por aquilo que ele procura como resultado da compra, ou seja, uma imagem vaga de um objeto de desejo. Desejo este que, segundo Bigal (1999), é estimulado pelas relações óticas, acústicas, visuais e significantes da peça publicitária, permitindo ao receptor encontrar nela a sua cultura, a sua história, a sua configuração, o seu modo de ser e de viver.

Muitos anúncios, então, usam de argumentos racionais para falar sobre a existência e a necessidade do uso de determinado produto, já outros evocam funções mágicas, transformando o produto num objeto de desejo e realização pessoal, o que caracteriza muito a publicidade contemporânea, frente ao crescimento do consumo.

\section{0 jogo do Desejo}

Pode-se afirmar que hoje, argumentar torna-se uma atividade discursiva que tem como meta além da racionalidade, discutir a importância e a influência que o objeto tem na vida do destinatário, uma vez que o interesse do consumidor, nesse caso, está mais na satisfação que pode obter com a busca, do que no próprio objeto da busca.

A busca pela razão direcionada no início da publicidade, por um ideal de verdade depende agora, das experiências individuais e sociais do sujeito, compartilhadas pelos membros de um determinado grupo. Como suas concepções do que é a verdade se confundem com as adotadas pelos membros desse grupo, o sujeito tenta, pela busca da influência, fazer com que o grupo compartilhe dos mesmos propósitos e crenças do seu mundo. Para isso precisa garantir a eficácia da sua argumentação, usando uma variante lingüística que deve ser do domínio de uma mesma tribo ou acessível a ela, para garantir a veracidade do que é afirmado.

O fato é que a comunicação se desenvolveu junto com a configuração da sociedade contemporânea e o "estar junto" pode ser analisado no discurso através da interação e da credibilidade que o sujeito, responsável pela fala passa ao seu protagonista, persuadindo-o a endossar a relação de troca que lhe é proposta. Neste cenário é construído o contrato de comunicação, responsável pela organização da matéria lingüística adotada pela publicidade.

A partir da movimentação social, que forma uma complexidade de agrupamentos sociais, a publicidade cria discursos com os quais as tribos se identificam e compartilham experiências, participando ativamente da constante mudança de significados na interpretação das mensagens e das mudanças de estratégias no contrato de comunicação.

Como as pessoas hoje partilham de novas experiências acabam por estabelecer trocas simbólicas que passam a compor o cimento social de determinado discurso, expressando em palavras o imaginário coletivo de um segmento de consumidores, que possuem muitas coisas em comum com outras tribos. Para Maffesoli, a comunicação contemporânea é como um sistema total, uma 
entidade que extrapola a consciência dos sujeitos que fazem parte do processo comunicativo, ao adotar uma "mescla de palavras, de gestos, de objetos, que remetem a uma poética globalizante." (2005, p.52)

Essas mudanças de relações ocasionarão profundas alterações no discurso publicitário, no que se refere a novos parceiros, novas visões de mundo e modelos de negócio, uma vez que o raciocínio desenvolvido pelas novas tecnologias é o hipertexto, em que os sujeitos se mesclam em vários enunciadores de mensagens colaborativas. Essas transformações afetarão de forma marcante o mercado da comunicação e a forma de interagir nesse novo contexto.

Mas para Charaudeau (2006), a publicidade atual ainda adota como dispositivo argumentativo, os elementos e procedimentos que envolvem várias possibilidades de uso em diferentes textos, que são:

- Um propósito sobre o mundo que tenha importância para alguém quanto à sua legitimidade, como às qualidades e utilidades de determinada marca.

- Uma proposição em que um sujeito que se empenhe em relação a esse questionamento, tentando estabelecer uma verdade que torne aceitável ou legítimo o propósito.

- A persuasão, que envolve um outro sujeito, que imbuído pelo mesmo propósito, torna-se alvo da argumentação. O sujeito que argumenta direciona-se para ele com o objetivo de levá-lo a partilhar das mesmas verdades que fazem parte do seu mundo.

Em caso de rejeição, é convencido de que existem outras maneiras de se obter os resultados anunciados pelo uso do produto. Para ser aceito, o sujeito comunicador reforça o que diz com argumentos que garantam a credibilidade da instância produtora.

A partir dessas perspectivas sociais, Charaudeau (1983) postula a existência de uma dupla razão de falar sobre a realidade: a razão demonstrativa e a razão persuasiva. A primeira estabelece ligações de causalidade a partir de procedimentos baseados na lógica dos fatos para falar sobre o mundo. Já a segunda, precisa provar, com a ajuda de argumentos, que essa realidade é a verdadeira.

A logicidade assume assim, uma importância fundamental, mas não é tudo no discurso argumentativo, pois à razão persuasiva podem se juntar razões demonstrativas de um fato que repousa sobre o princípio da novidade. O sujeito falante tem o papel de prover a informação, cuja validade depende da relação com o outro e também da variante lingüística que seja decifrável para ambos, bem como a aceitação do estatuto de autoridade do sujeito emissor em relação ao destinatário, como aparece no exemplo:

\section{É assim (eu afirmo isto) porque eu vivi esta situação.}

Propósito: O novo produto da marca X procura competência de qualidade.

Proposição: Se você quer "encontrar qualidade em um produto" então use $X$.

Persuasão: Você não pode deixar de usar o produto da marca X.

A publicidade recorre a este argumento de autoridade ao relatar testes e experiências científicas para verificar os resultados que correspondem às vantagens de determinado produto e a veracidade do que é afirmado, uma vez que promete eliminar as rugas em duas semanas de uso.

Complementando seu estudo sobre "o modo de organização argumentativo", Charaudeau (2008) analisa a relação lógica que se insere nesse discurso composta de uma afirmação de partida, uma afirmação de chegada e de uma ou várias afirmações de passagem, pertencentes às categorias da Implicação e da Explicação.

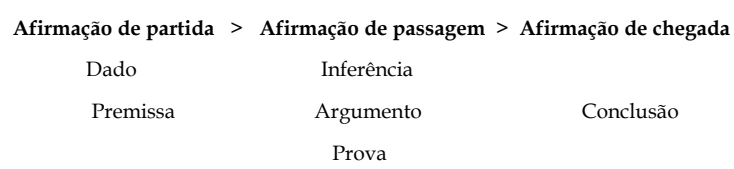

Quando se afirma: Ou o produto X ou o caos, define-se um procedimento da lógica argumentativa usada pelo discurso publicitário, que pode ser expresso por:

1) Se usar o produto $X$, tem-se a ordem.(dado)

2) Se não usar o produto $X$, tem-se o caos e não a ordem.( argumento)

3) Logo, é preciso usar o produto $X$ para alcançar a ordem.( conclusão)

Essa asserção representa um universo de crença sobre o modo como os fatos se apresentam na experiência, ou mesmo o conhecimento que se tem, da realidade. Assim, esse universo deve ser partilhado pelos interlocutores implicados na argumentação de tal forma que se estabeleça a prova que torna verdadeira a ligação entre as duas primeiras afirmações. Desenvolve-se aqui o pensamento de que, do ponto de vista do sujeito que argumenta (argumentador), o interlocutor deve se sentir incitado a aceitar como verdadeira sua proposta. Caso isso não aconteça, deverá contra argumentar, criando proposições que contradizem a proposta inicial, com base em suas experiências de mundo.

A persuasão conduz o indivíduo a aderir ao produto, com implicações mais complexas que o simples uso, por envolver aspectos inconscientes de idealização e de identificação com o sujeito comunicador. Ela atua sobre o destinatário mediante mecanismos de identificação com a situação que presencia no ato de fala, pois apela para seus sentimentos e emoções, a partir de significações subjetivas que vão formando a imagem do produto como única no mercado.

A publicidade na tentativa de transcender a questão do real e da verdade através da busca pela sedução realizou-se através da forma mais pronunciada de uma 
tentativa de persuasão. Isto se explica pelo fato de que a sedução, ligada a planos mais afetivos e sensoriais, ou seja, a modos mais primitivos de funcionamento psíquico, teve como conseqüência um relaxamento da realidade e da crítica.

Portanto, ao oferecer de modo sedutor um produto que supostamente irá satisfazer um desejo, a publicidade estabelece a correspondência entre o mundo real e o desejo, instaurando uma nova realidade em que o importante é o efeito de verdade que foi criado na mensagem, como se observa no texto: Andar ficou para trás. (Tênis Adidas)

Tal enunciado remete à situações linguageiras de um mundo formado pelas tribos de pessoas que praticam esportes radicais e ao tênis Adidas, que propaga a nova tecnologia Bounce, que permite maior segurança nas atividades físicas. Tal enunciado tem um sujeito coletivo a sustentá-lo e uma verdade divulgada no mundo esportivo, que é o uso adequado de um tênis para dar segurança aos esportes radicais. De modo implícito, dirige-se também às pessoas mais velhas que desistiam de fazer caminhadas por falta de segurança, com medo de cair e fraturar um membro.

Por falar a um consumidor múltiplo e contemporâneo, a publicidade não se ajusta mais a classificações sociais esquematizadas, uma vez que "a classe não pode servir mais como um dispositivo ou uma categoria mobilizadora através da qual todos os variados interesses e identidades possam ser representadas numa peça publicitária." ( HALL, 2005, p. 21)

Como se observa, a lógica do desejo no contexto da sociedade atual trabalha comportamentos distintos na busca de um status social, através de um consumidor que assume diferentes papéis na sociedade sem alguma lógica ou padrão que os unifique, fazendo com que o efeito da verdade de um discurso possa assumir conotações imprevisíveis sobre a mesma situação vivida em outro segmento de consumidor.

Ao discutir a lógica da marca pelo discurso da identificação, Semprini (2006) defende que a essência do consumo hoje, está em sua capacidade de suscitar associações simbólicas intercambiáveis com os consumidores através de operações mentais de alto grau de abstração, em que o objeto de troca passa a ser o próprio sentido. Isso porque o excesso de informações está formando um consumidor imune aos argumentos comuns, permitindo que o aspecto simbólico implícito no anúncio estabeleça um vínculo entre ele e o produto, concedendo-lhe poder na decisão da compra. Cada vez mais será o consumidor que argumentará, criará a proposta e se empenhará em estabelecer as verdades sobre o produto, tornando-se seletivo e crítico em relação ao contrato de comunicação estabelecido.

Na sua fala cotidiana a publicidade ainda instaura formulações lingüísticas, constituídas a partir de nomes de produtos ou termos em voga na época em que o produto foi lançado no mercado, segundo acepções que diferenciam do seu termo original, mas com conotações que se aproximam do seu nome e ainda reforçam seu sentido persuasivo.

Aparecem na Revista do Globo, editada de 1929 a 1967, vários casos que servem de exemplo, como o do anúncio do inseticida Detefon ${ }^{2}$. A palavra "detefonizar", que está em destaque, é usada como verbo de ação no título do anúncio, remetendo ao nome do produto, também destacado à margem do corpo do texto. Os leitores da RG já conheciam o produto, que vinha sendo divulgado em anúncios anteriores e por esse motivo, possivelmente, compreenderam o sentido da palavra que não era usada na língua cotidiana.

Segundo Dorfles (1965, p. 212), "a prévia comunicação de um 'nome chave', torna compreensível uma mensagem que, de outro modo, não teria sido possível". Por esse motivo, na linguagem da publicidade, há empréstimos lingüísticos considerados viciosos de palavras derivadas de outras línguas, que poderiam ser substituídas por termos que fazem parte do léxico da língua nacional. Sandmann (1993) condena em suas obras, o uso desses estrangeirismos, que aparecem como desvios das normas ortográficas, mas ganham força através de uma simbologia gráfica distinta, com a vantagem de serem formados por elementos lingüísticos providos de significado. O discurso publicitário tradicional ao ser decodificado de modo imediato e prendia-se a normas precisas da linguagem cotidiana, garantindo com isso a possibilidade de uma única interpretação. Por isso, necessitava sistematizar as figuras retóricas de modo preciso e eficaz.

Sant'Anna (1996, p. 86) analisa a publicidade a partir dessas concepções, afirmando que

o artista que trabalha para a publicidade deve buscar a verdade sensorial subjetiva, deve recorrer ao realismo concreto, expressão viva da realidade, com aquilo que o público se sente familiarizado, preferencialmente sobre todas as combinações das tendências intelectuais da arte e da vida.

Diz ainda o autor, que a arte publicitária sempre ficou subordinada à arte de vender, por isso o público assumia o caráter da maior importância, já que tudo era feito em função dele, o que impõe condições de limitações ao que é criado. O problema, então, para Sant'Anna, "não é imitar a natureza, mas obter a essência do sujeito representado" (1996, p. 87).

Com isso, a evolução da produção de mensagens acompanhou a evolução da atividade de interpretação e as práticas de consumo, pois houve uma sedimentação de um "capital cultural" dos sujeitos interpretantes sobre a publicidade até os dias atuais, o que permitiu a decodificação dos anúncios ao longo do tempo. Por isso, uma análise dos traços estilísticos de um discurso suscitará novas respostas, que não serão precisamente as mesmas num período e no outro, pelas referências a 
categorias institucionais ou à sua dimensão de uso, determinadas pelas variantes lingüísticas e pelos costumes vigentes numa sociedade.

Assim como Charaudeau, também Adam (1992) aponta caminhos para a questão da heterogeneidade constitutiva dos diferentes gêneros de textos, atribuindo as diferenças entre eles na configuração pragmática e na complexidade.

O mesmo aconteceu com a publicidade que, feita para uma época e para uma certa sociedade, carrega consigo uma carga semântica e estética que só faz sentido em determinado contexto, mas é interpretada de forma diferenciada em outras culturas. "Por isso, o estilo cotidiano pode, em certas épocas, dar forma e figura ao conjunto da sociedade" (MAFFESOLI, 1995, p. 71).

Para o autor, esse estilo de vida enfatiza os jogos da aparência e os aspectos imateriais da existência, pelo manejo das imagens ou pelo consumo desenfreado dos objetos, o que faz prevalecer não mais a produção ou o trabalho, mas um querer viver bem através da satisfação dos desejos criados ou confirmados pela publicidade. A crescente desmaterialização do consumo impõe novas formas lingüísticas ao discurso argumentativo, direcionando a fala do sujeito comunicador no sentido dos aspectos intangíveis do produto, uma vez que o objeto de troca deixa de ser o próprio produto e passa a ser o seu significado.

Na sociedade contemporânea, caracterizada pela sofisticação do consumo, as noções estabelecidas pelo discurso argumentativo entre as necessidades e os desejos são cada vez mais difíceis de serem interpretadas, uma vez que o excesso de ofertas e opções de crédito ilimitadas tornam possível o acesso a bens que extrapolam as necessidades tidas como naturais, na busca da distinção, do conforto, da segurança e do bem viver.

Com isso, o consumidor satisfaz sua carência material ou consumista através do deslocamento de uma realidade concreta para uma realidade intangível, que segundo (LIPOVETSKY, 2004) transforma a dinâmica da publicidade para um consumo mais emocional e experiencial ligado ao status, tornando o produto secundário frente a sua marca.

Esses universos de referência se encontram no espaço da cidade, da natureza e de outros lugares conhecidos, e correspondem a práticas sociais, familiares e de comportamento. Também estão implícitos em espaços míticos preexistentes como a religião, a literatura, os filmes entre outros; em espaços simbólicos como o exotismo, a aventura, o status, incorporados ao próprio produto, pois este recebe muitos valores simbólicos agregados ao seu uso.

\section{Argumentando alguns aspectos conclusivos}

A análise sobre o modo de organização argumentativo dos anúncios revela o projeto de fala do enunciador, que pretende transformar os leitores de anúncios em consumidores efetivos de mercadorias, fabricando uma ima- gem de destinatário que não pode recusar o apelo de venda. Esse sentido se revela no discurso, na relação, no limite de um sistema sígnico com o outro, mostrando que uma linguagem não é mais importante do que a outra. Ao contrário, elas se complementam, se atravessam, umas completando o significado de discursos anteriores.

O produto ocupa, então, uma função quase mágica, como estratégia para convencer o sujeito de que ele tem uma carência afetiva, o que provoca de sua parte uma ação para tentar satisfazer esse desejo através do consumo do objeto e de todos aspectos intangíveis que são prometidos através do discurso argumentativo da publicidade. É no limite desse movimento, que na realidade não acaba jamais, mas que se reafirma de tempos em tempos, que se constroem as estratégias discursivas do texto como prova de um conjunto de "possibilidades interpretativas", que atingem o leitor e possível consumidor de maneira diferenciada.

Ao se falar em estilo de um gênero discursivo, deve-se levar em consideração o conjunto de procedimentos formais que o caracterizam, como resultado da adequação lingüística aos propósitos de sua criação. No discurso publicitário, por exemplo, os endereços, nomes de agências, marcas de produto, funcionam como dados históricos que podem ser estudados para caracterizar a publicidade num período, pois formam o pano de fundo da história de uma cidade e informam sobre vários aspectos desse mundo real, que os leitores desconhecem.

A Publicidade é identificada como de interesse comercial, pois tem a intenção de promover lucro ao conquistar, ao aumentar e ao tentar manter clientes. $O$ discurso publicitário aparece, então, como essencialmente argumentativo e usa da persuasão, identificada através das referências ideológicas do destinatário, para fazê-lo sentir uma falta e predispor-se favoravelmente, a supri-la, convencido pelos argumentos dados. Esse procedimento impede, segundo Adam (1992), qualquer outra atitude que não seja, o consumo do produto anunciado.

No interior do discurso publicitário, cada vez mais se elogiam ou condenam determinados estilos de vida, fomentam-se ou silenciam-se ideologias, convencem-se pessoas sobre a utilidade das coisas, de certos hábitos e condutas e vende-se um oásis de sonhos, de euforia e de perfeição, com a intenção de ocultar os aborrecimentos do dia-a-dia e proclamar o prazer proporcionado pelos objetos de consumo. Para seu reconhecimento então, se faz necessário a distinção dos esquemas que identificam cada uma dessas organizações discursivas, em suas estruturas mais ou menos homogêneas e hierarquizadas, identificando uma dominante: " a arte de argumentar em um contrato de comunicação que tem como fim a posse ou não de um produto."

Os três elementos que interagem na organização argumentativa da publicidade, segundo Charaudeau (1983), que foram analisados nos anúncios da RG, escritos em prosa e verso, muitas vezes não aparecem de forma linear; pois quando o contrato é implícito, o dispositivo não 
é precisado, identificando as asserções simples como participantes de um propósito, de uma proposição e de um ato de persuasão.

Constatou-se também, que cada vez mais, o consumo torna-se parte importante da vida e o cimento social de relações, agregando- se definitivamente à subjetividade do indivíduo. Esse consumo atual, desmaterializado e carregado de significados é relevante no contrato de comunicação realizado pela publicidade, já que a abstração aparece como matriz de seu funcionamento o que leva a argumentar menos sobre as utilidades materiais do produto e mais sobre o que ele representa e pode mudar a vida de uma pessoa.

Como a produção publicitária sempre foi determinada pela existência ou não da concorrência, na ausência dela, o produto era oferecido de forma direta, como imposição sem alternativa. Já a existência de uma concorrência obrigou o publicitário a usar um discurso de valorização do produto, apoiado pelos valores agregados na marca.

Tais valores revelam-se na estrutura lingüística e icônica do anúncio e os sujeitos aderem ou não ao que é proposto e, a partir daí, formam uma consciência social, que é determinante no processo de compreensão do anúncio, mesmo que de forma inconsciente. O sujeito se dilui então, na consciência do grupo social, de forma radical, quando é determinado pelo que é pré- construído no discurso, tornando-se parte da engrenagem e não um ser especial.

Torna-se necessário então, construir, para o publicitário, uma máscara de anunciante honesto e interessado apenas no bem-estar do consumidor, que é motivado a comprar não só o produto, mas tudo aquilo que ele promete proporcionar e que faz parte do imaginário coletivo de uma sociedade. O objeto de venda se transforma assim, mais na satisfação de um desejo do que na sua necessidade material.

Ao criar a singularização como procedimento retórico no início dos anúncios, os produtores encontraram novas formas argumentativas para falar da publicidade como produtora de significados em uma estratégia revitalizadora do mercado econômico. Mas, este sentido só pode acontecer em um dado movimento enunciatório.

É na enunciação, no processo de revitalização do sistema da língua, no resultado de um processo argumentativo que a publicidade coloca em movimento estratégias que seduzem o leitor. Em cenas cotidianas ou poéticas, reais ou imaginárias, ela evidencia o processo da argumentação, determinando modos de vida, sistemas sociais, padrões idealizados por pessoas que se apresentam e que querem viver com intensidade o espetáculo diário da vida humana mFAmECos

\section{NOTAS}

1. A dificil arte de redigir anúncios. RG n.301, de 09/ 08/1941, p.6.
2. Inseticida Detefon: RG n.478 de 05/03/1949, p.42.

\section{REFERÊNCIAS}

ADAM, Jean Michel. Eléments de linguistique textuelle. Liège: Mardaga, 1990.

BIGAL, Solange. Afinal, o que é criação publicitária? - ou o estético na publicidade. São Paulo: Razão Social, 1999.

CASTRO, Maria Helena Steffens de. O Literário como Sedução: a publicidade na Revista do Globo.Porto Alegre: EDIPUCRS, 2004.

CHARAUDEAU, Patrik. Langage et discours. Paris: Haclutte, 1983.

Grammaire du sens et de l'expression. Paris: Haclutte. 1992.

_ (Tradução Ângela Corrêa) Discurso das Mídias. São Paulo: Contexto, 2006.

Linguagem e Discurso: modos de organização. São Paulo: Contexto, 2008.

DORFLES, Gillo. Novos ritos, novos mitos. São Paulo: Martins Fontes, 1965.

FERRER, Eulálio. El linguage de la publicidad. México: Tezontle, 1994.

HALL, Stuart. A identidade cultural na pós- modernidade. Rio de Janeiro: DP\&A, 2005.

JAKOBSON, Roman. Lingüística e comunicação. São Paulo: Cultrix, 1971.

LIPOVETSKY,Gilles. O império do efêmero. São Paulo: Companhia das Letras, 2004.

MAFFESOLI, Michel. A contemplação do mundo. Porto Alegre: Artes e Ofícios, 1995.

SANDMANN, Antônio José. A linguagem da propaganda. São Paulo: Contexto, 1993.

SANT'ANNA, Armando. Propaganda teórica, técnica e prática. São Paulo: Pioneira, 1996.

SEMPRINI, Andréa. A marca pós- moderna. São Paulo: Estação das Letras, 2006.

VALÉRY, Paul. Escrito sobre Leonardo Da Vinci. Madrid: Visor, 1987. 